\title{
Safety and efficacy of naltrexone for weight loss in adult patients - a systematic review
}

Agnieszka Kulak-Bejda ${ }^{1}$, Grzegorz Bejda², Napoleon Waszkiewicz ${ }^{1}$

\begin{abstract}
1Department of Psychiatry, Medical University of Bialystok, Bialystok, Poland ${ }^{2}$ Department of Human Philosophy and Psychology, Medical University of Bialystok, Bialystok, Poland
\end{abstract}

Submitted: 26 March 2018; Accepted: 22 July 2018

Online publication: 10 September 2020

Arch Med Sci 2021; 17 (4): 940-953

DOI: https://doi.org/10.5114/aoms.2020.96908

Copyright $\odot 2020$ Termedia \& Banach

\begin{abstract}
Introduction: This is a report of a systematic review of the safety and efficacy of naltrexone or naltrexone/bupropion on weight loss.

Material and methods: The databases Medline, PubMed, and Embase as well as the Cochrane Controlled Trials Register for randomized controlled trials were searched for studies published from January 1966 to January 2018. A meta-analysis, randomised controlled trials, controlled trials, uncontrolled trials, cohort studies and open-label studies were analysed.

Results: Of 191 articles, 14 fulfilled the inclusion criteria: 1 meta-analysis, 10 randomized controlled trials, and 3 studies without randomization were found. In these studies, the efficacy and safety of naltrexone/bupropion in obesity were analysed. In the majority of these studies, patients with at least $5 \%$ or $10 \%$ weight loss, as a primary outcome, were investigated. Generally, naltrexone/bupropion treatment can be a promising therapy for obese patients, including when combined with mental health treatment.

Conclusions: Based on these studies, it can be said that naltrexone/bupropion treatment is effective in the weight loss of overweight subjects. The naltrexone/bupropion treatment was well tolerated by the patients, and side effects were rarely reported.
\end{abstract}

Key words: obesity, therapy, naltrexone, bupropion, systematic review.

\section{Introduction}

In recent years, obesity in adults and children has been increasing and has started to become a leading cause of death. It is one of the greatest public health threats in Europe and the world [1]. The World Health Organization (WHO) assessed that excessive weight is the cause of death of almost 3 million people and brings about disability amongst 35.8 million people annually [2]. In adults, obesity criteria include a body mass index (BMI) over $30 \mathrm{~kg} / \mathrm{m}^{2}[3]$.

Obesity is a chronic and multifactorial disease involving the accumulation of subcutaneous and visceral fat, which gives rise to the development of many cardiometabolic diseases [4]. Diabetes, stroke and heart disease are associated with obesity. Unfortunately, many of the complications brought by obesity lead to death, which might be averted through a change in lifestyle. There are different theories about obesity's mechanisms, such as inflammation, inflammasome activation, insulin resistance,

\author{
Corresponding author: \\ Dr. Agnieszka Kulak-Bejda \\ Department of Psychiatry \\ Medical University \\ of Bialystok \\ 1 Brodowicza Sq \\ 16-070 Choroszcz, Poland \\ E-mail: agnieszka.kulak. \\ bejda@gmail.com
}


adipokine balance, and abnormalities in lipid metabolism and endothelial function [4]. Some of the newest data have shown that obesity is characterized by low-grade chronic inflammation caused by increased secretion of pro-inflammatory cytokines and adipokines by the macrophages and adipocytes present in adipose tissue [5].

Almost all obese patients should have additional behavioural treatment. There are many programmes that focus on behavioural and lifestyle modifications such as the Diabetes Prevention Programme (DPP) run by the National Health Service (NHS) in the U.K. or the Look AHEAD Action for Health in Diabetes operated by the National Institutes of Health (NIH) in the U.S. [6]. However, lifestyle modification and weight loss alone are usually ineffectual [7].

Another factor responsible for weight gain of pharmacological action is blockage of $5 \mathrm{HT} 2 \mathrm{c}$ serotonin receptors by several first-generation and the majority of second-generation antipsychotics. It is known that $5 \mathrm{HT} 2 \mathrm{C}$ receptors are engaged in appetite regulation $[8,9]$.

Moreover, it was reported that an opioid receptor blocker blocked the central opioid receptors, thus decreasing the preference for toothsome foods [10].

In 2015, the first clinical practice guidelines for the pharmacologic management of obesity were published. These directives were created by the Endocrine Society (a task force of experts), the European Society of Endocrinology and the Obesity Society [11]. However, the Food and Drug Administration (FDA) has endorsed only a few medicaments for the treatment of obesity. One of the newest medications is the combination of bupropion and naltrexone [6].

Naltrexone is a $\mu$-opioid receptor antagonist commonly used for treatment of opioid addiction and alcohol dependence [12]. Possibly, naltrexone reduces food consumption through the blockage of $\beta$-endorphin action at the $\mu$-opioid receptor as well as preventing autoinhibition of pro-opiomelanocortin neurons [13]. The first pass of naltrexone's metabolism is $5-40 \%$ oral bioavailability. Both primal naltrexone and the 6 - $\beta$-naltrexol metabolite are active forms. Mostly, naltrexone is eliminated by the kidneys. Retrospectively, the elimination half-life of naltrexone and 6- $\beta$-naltrexol is long - 4-13 h [13-16].

In turn, bupropion is a norepinephrine-dopamine reuptake inhibitor which is currently prescribed for treatment of depression, seasonal affective disorder and also as support during smoking cessation [17]. Dopamine and noradrenaline stimulate pro-opiomelanocortin neurons in the hypothalamus. The mean elimination half-life of bupropion is very long - $21 \pm 9 \mathrm{~h}$. It is metabo- lized by humans, resulting in three active metabolites: hydroxybupropion, threohydrobupropion and erythrohydrobupropion. Eighty-seven percent of bupropion is eliminated by the kidneys and $10 \%$ in faeces $[14,15,18]$.

The effect of the combination of naltrexone and bupropion is not completely clear. There is a theory that naltrexone could have an influence on the neurological reward pathways in the brain, while bupropion suppresses the appetite [12].

The purpose of the current work was to systematically present the safety and effectiveness of naltrexone or a combination of naltrexone and bupropion for weight loss in patients with antipsychotic-associated obesity, in comparison with patients suffering from overweight without any antipsychotic treatment.

\section{Material and methods \\ Study population}

The study population consisted of adult patients undergoing naltrexone or naltrexone/bupropion treatment.

\section{Study design}

The researchers analysed the relevant metaanalyses, randomized controlled trials (RCTs), controlled trials, uncontrolled trials, cohort studies, case-control studies, and cross-sectional studies. Studies with a population of fewer than 5 patients were excluded.

\section{Intervention}

As an intervention, we included therapy using naltrexone or a combination of naltrexone and bupropion.

\section{Outcome measure}

To assess the safety of the therapy, we analysed the number of patient discontinuations due to adverse events in the treatment group compared to those in the placebo or control group. We also analysed the number of significant adverse events reported in the studied groups.

\section{Methodological quality}

We assessed the quality of all articles that fulfilled the inclusion criteria. To evaluate the quality of RCTs, we used the Jadad scale, the impact factor of the journal in which the trial was published, and evidence of statistics using intention-to-treat analysis. The Jadad scale [19] contains two questions to determine appropriate randomization and study masking, along with questions that evaluate the reporting of withdrawals and dropouts that require 
a yes or no response. Five total points are possible on the scale, in which a higher score indicates superior quality. We also used the Cochrane Collaboration's tool to assess the risk of bias of RCTs [20].

\section{Categorizing evidence}

We categorized evidence according to the study design, using a hierarchy of evidence in descending order according to quality [21] and reviewed the highest level of available evidence for each intervention in detail.

\section{Literature search}

Two independent reviewers screened titles and abstracts for relevance. The search included four electronic databases, namely, Medline, PubMed, Embase, and the Cochrane Central Register of Controlled Trials for studies reporting meta-analyses, RCTs, controlled trials, uncontrolled trials, cohort studies, case-control studies, and cross-sectional studies for therapy of patients with irritable bowel syndrome (IBS). We restricted our search to studies published between January 1966 and January 2018. Only English-language articles were included. We searched for the following terms: 'obesity' OR 'overweight' AND 'naltrexone/bupropion'.

The search of PubMed, the Cochrane Database, and Embase produced 191 articles, most of which derived from PubMed and all of whose titles and abstracts we read. It was possible to exclude 177 articles, none of which fulfilled the search criteria. After reading the full texts, we considered 14 articles: 1 meta-analysis, 10 RCTs, 3 studies without randomization and retrospective analysis (Figure 1).

\section{Publication bias}

We performed data extraction for all 14 full texts, not blinded to author or journal, using a predefined extraction sheet (available upon request). The type of information extracted included first author, publication year, quality assessment of the manuscript, mean age of participants, sex proportion, characteristics of patient treatment,

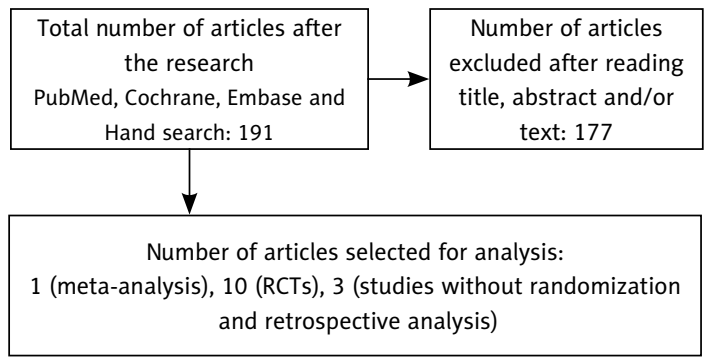

Figure 1. Flow chart for articles researching efficacy of naltrexone for weight loss in adult patients RCTs - randomized controlled trials. type of comparator, drug dose, number of participants in active and control groups, and outcome measure used to assess efficacy and safety.

\section{Results}

\section{Meta-analysis}

To date, only one meta-analysis was found analysing the efficacy of naltrexone in obesity [22]. In this study, naltrexone was one of five agents included in the meta-analysis. Generally, as a primary outcome, the studies found the proportion of patients with at least $5 \%$ weight loss and at least $10 \%$ weight loss, the magnitude of decrease in weight and discontinuation of therapy because of adverse events at 1 year. In this meta-analysis, participants had at least 5\% weight loss, with 55\% taking naltrexone/bupropion. Moreover, naltrexone/bupropion was associated with a significant amount of weight loss (5.0 kg) compared with the placebo (control group). However, compared with placebo, naltrexone/bupropion was associated with the highest odds of adverse event-related treatment discontinuation [22]. More specific information is included in Table I.

\section{Randomized controlled trials}

We included ten RCTs. One article focused on major adverse cardiovascular events in overweight and obese patients [23]. In this study, the time to the first confirmed occurrence of major adverse cardiovascular events (MACE) occurred in $90(2.0 \%)$ in the naltrexone/bupropion group. The components of the primary composite outcome included occurrence of cardiovascular death in 17 naltrexone/bupropion-treated patients. Adverse events occurred in 543 patients (5.2\%) [23].

Four studies [24-27], as a primary outcome, presented percent weight change at week 56 and proportion achieving $\geq 5 \%$ weight loss at week 56 [24-27]. Generally, in these studies, naltrexone/ bupropion resulted in significantly greater weight change at week 56 and a greater proportion of patients achieving $\geq 5 \%$ weight loss compared with the placebo [24-27].

In the newest paper, from 2017 [28], the authors presented, as a primary outcome, the percent change in body weight from baseline (day 1) to week 26. They used the standard dose of naltrexone/bupropion connected with comprehensive lifestyle intervention (CLI), a programme containing diet and exercise education. The results were promising. Subjects lost significantly more weight (8.52\%) compared to the control group.

One author investigated the cortisol response to naltrexone (cortisol levels at 3 PM and 4 PM on the naltrexone day were higher) and nausea responses to naltrexone. It was found that more 


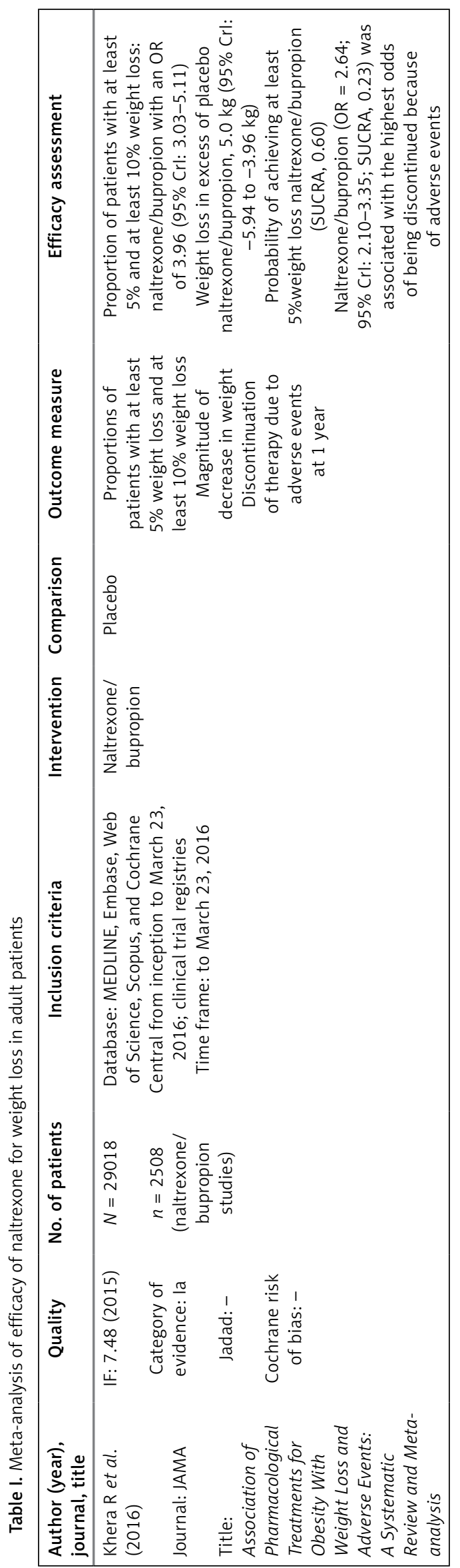

patients reported experiencing nausea on the naltrexone day) [29]. The changes at 56 weeks in the quality of life were measured by the Impact of Weight on Quality of Life-Lite (IWQOL-Lite) questionnaire [30]. This instrument showed that improvements in IWQOL-Lite Total Score were more significant in subjects treated with naltrexone/ bupropion [30].

From the psychiatric point of view, two RCTs $[31,32]$ were significant. These studies focused on the effect of naltrexone on body weight in patients with anti-psychotic treatment. In one, the patients in the naltrexone/bupropion group had significant weight loss $(-3.40 \mathrm{~kg})$ compared with weight gain $(+1.37 \mathrm{~kg})$ in the patients in the placebo group [31]. In the second study, there was no significant change in BMI. However, it showed that the olanzapine + naltrexone group displayed a significant decrease in fat and increase in fatfree mass, which suggests that the addition of naltrexone to olanzapine may attenuate olanzapine-induced body fat mass gain [32]. More details are included in Table II.

\section{Studies without randomization and retrospective analysis}

Three studies without randomization investigating the effectiveness of naltrexone were found. [33-35]. In one study [33], the Reward-Based Eating Drive (RED) scale (non-significant associations with naltrexone) and food-craving intensity (non-significant difference between naltrexone and placebo) were investigated as a primary outcome. Another study investigated the cortisol responses to naltrexone (increased on the naltrexone day) and nausea responses to naltrexone (mean level of nausea severity was $1.23 \pm 1$.3) [34]. The third article focused only as a secondary outcome on the percent change from baseline in body weight (increased slightly in continuous abstainers) [35]. In all three studies, the most common adverse event was nausea [33-35]. More details are included in Table III.

\section{Discussion}

Nowadays, obesity treatment goals include body weight reduction and weight maintenance after weight loss [36]. The basic strategy consists of an energy-reduced diet (of $500 \mathrm{kcal} / \mathrm{day}$ ), introduction of physical activity, behavioural modifications or pharmacological treatment [36]. Moreover, it is probable that the gene therapy-based strategy in modulating metabolism and treating metabolic disorders will be the future of obesity treatment [37].

As a treatment option for obesity, naltrexone/ bupropion has proved efficacious and safe. As 


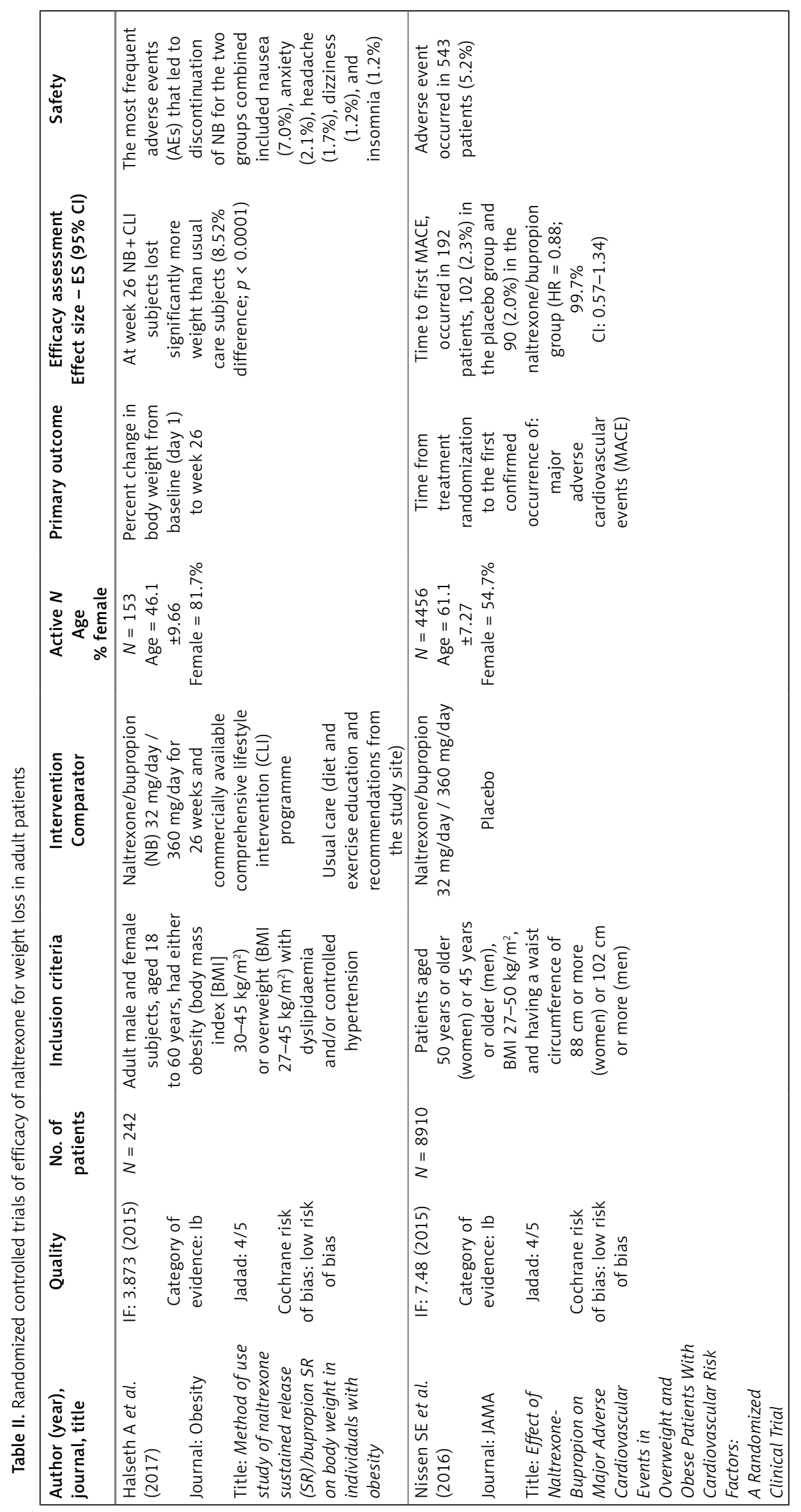




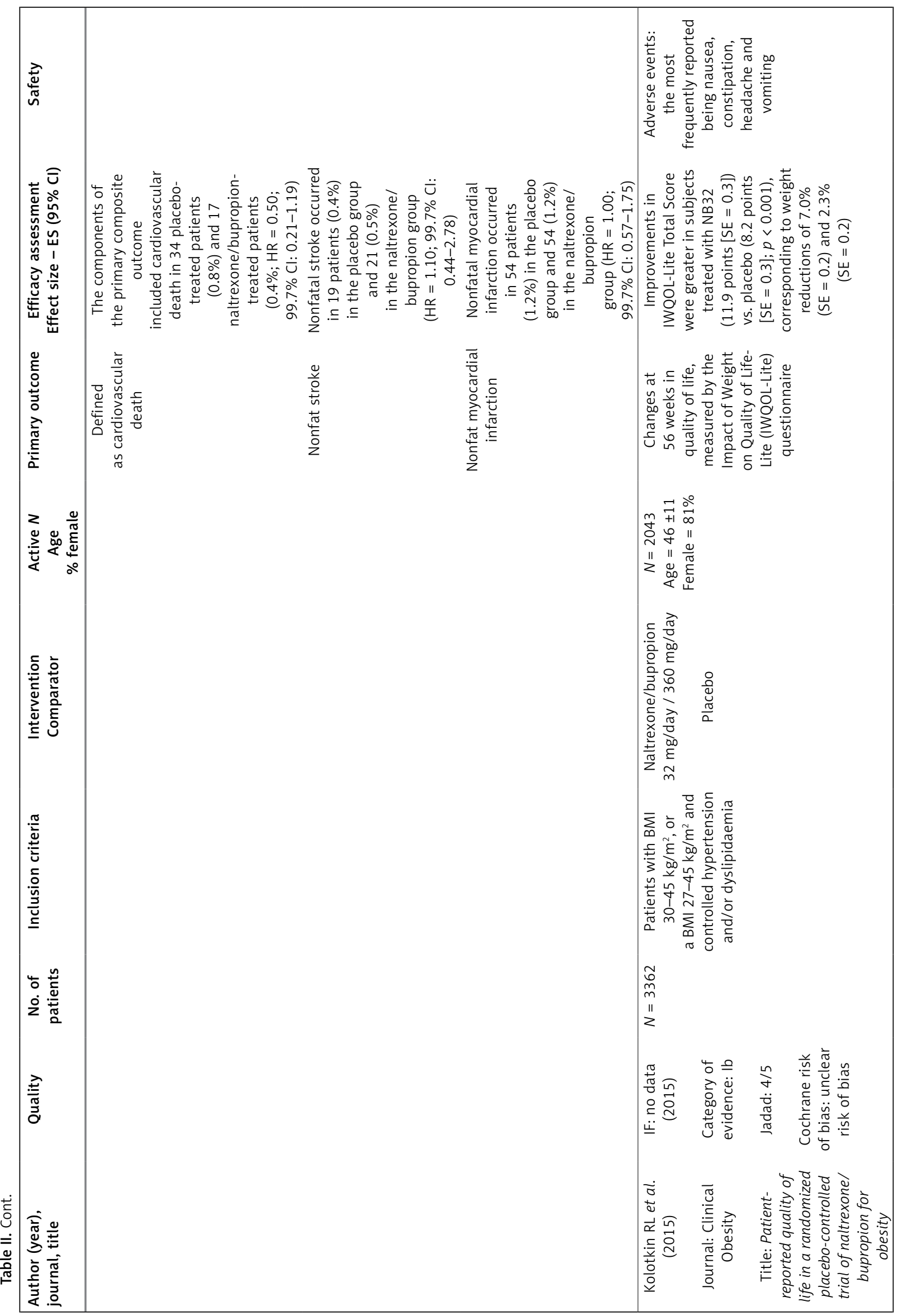




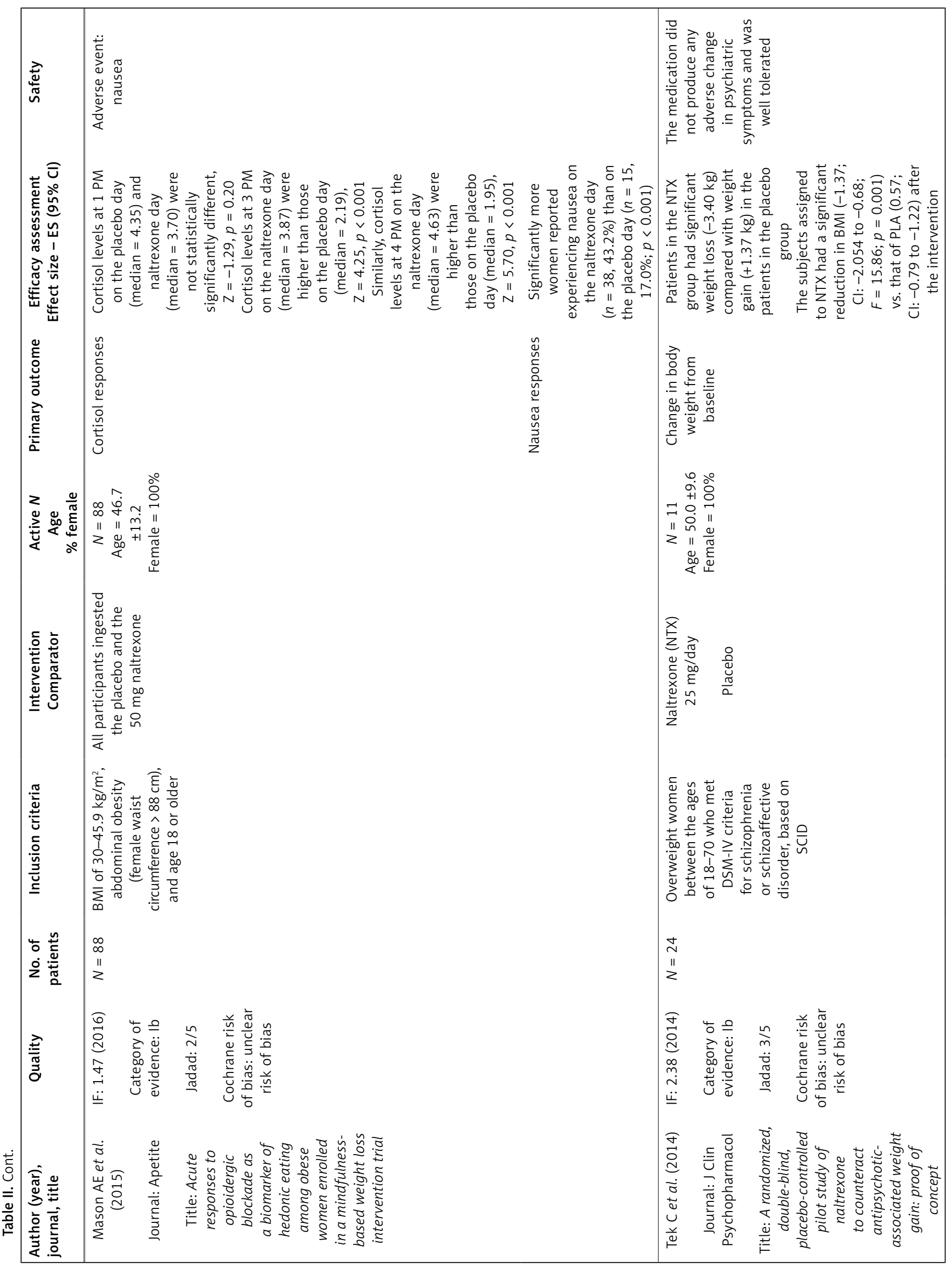




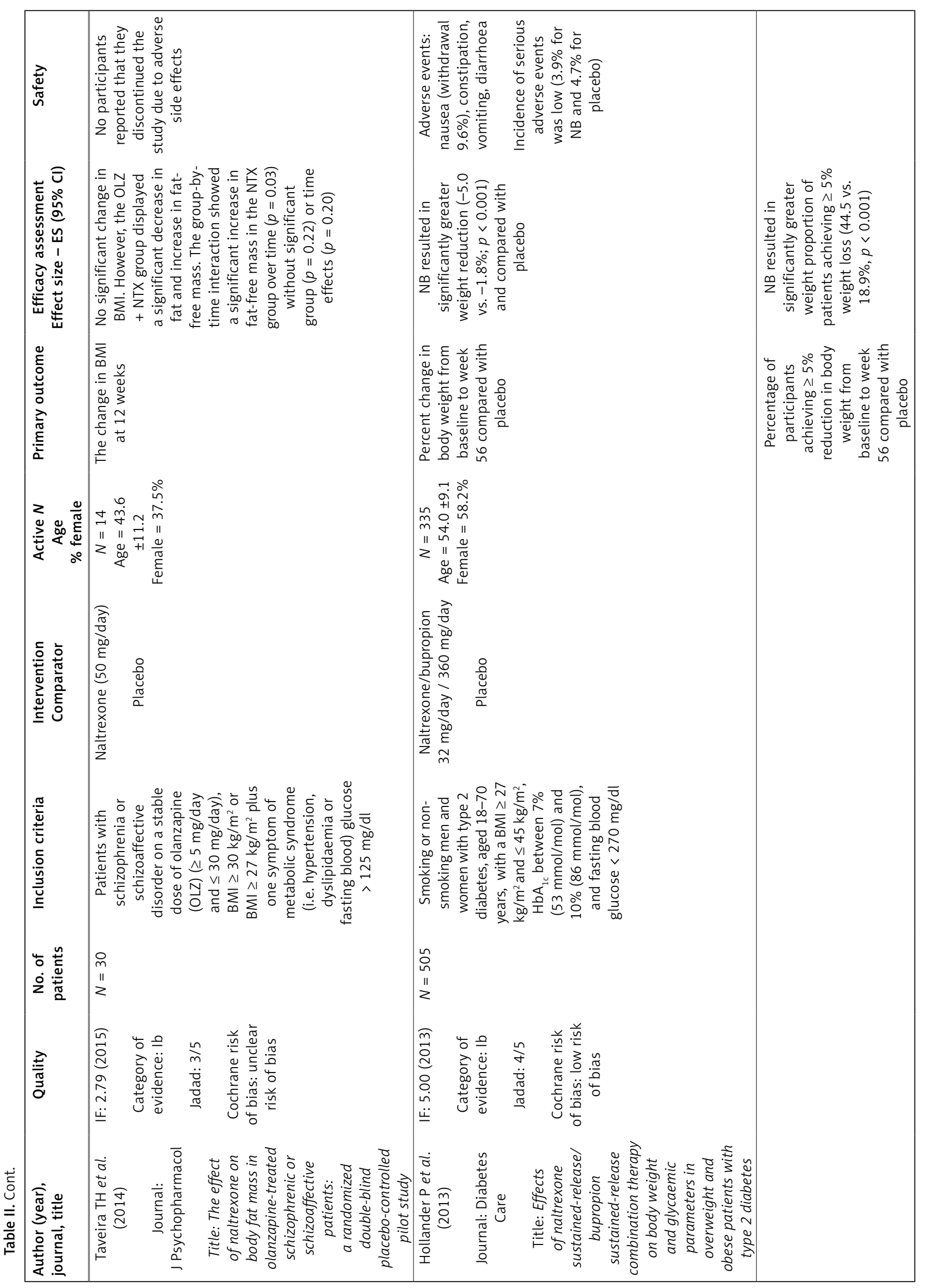




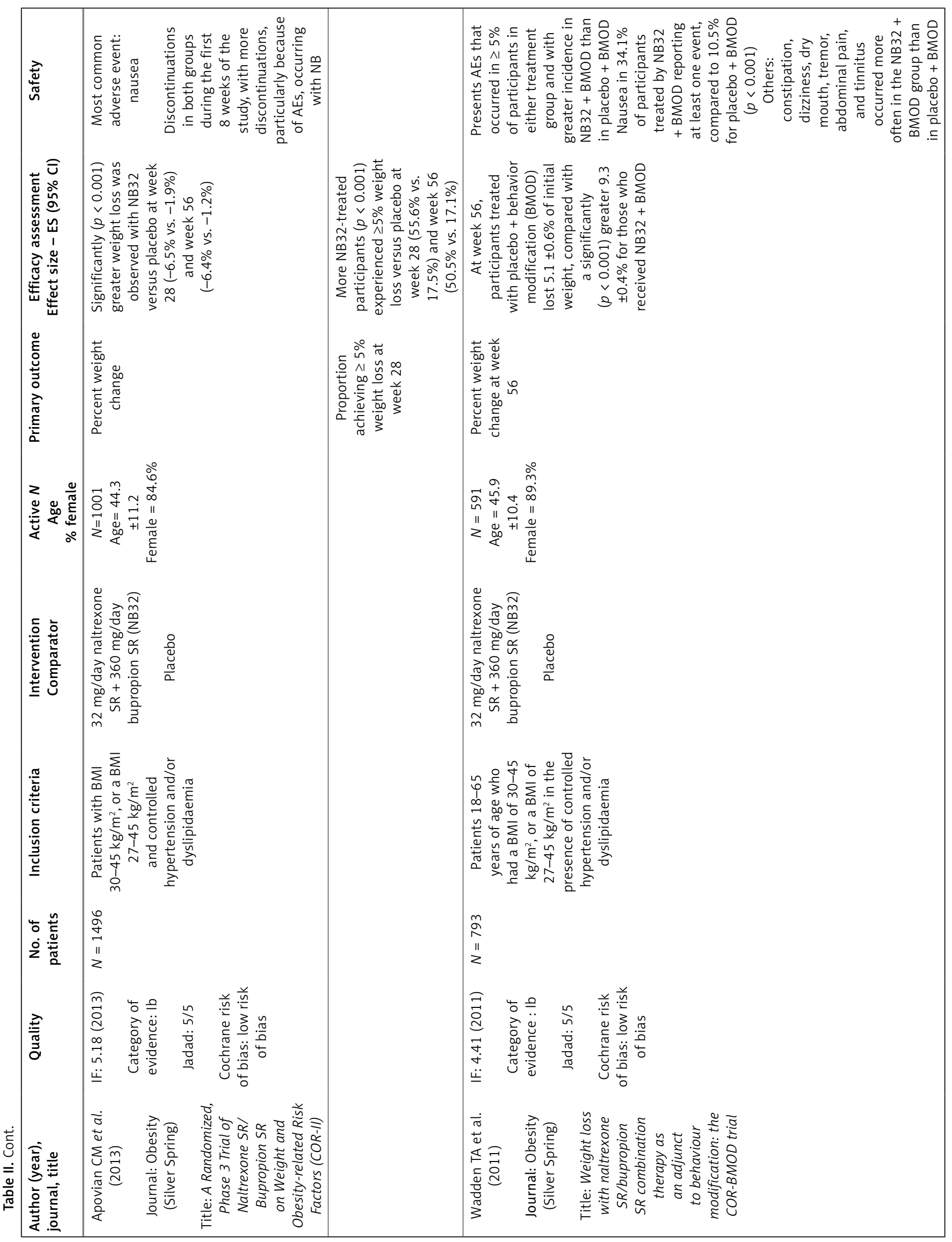




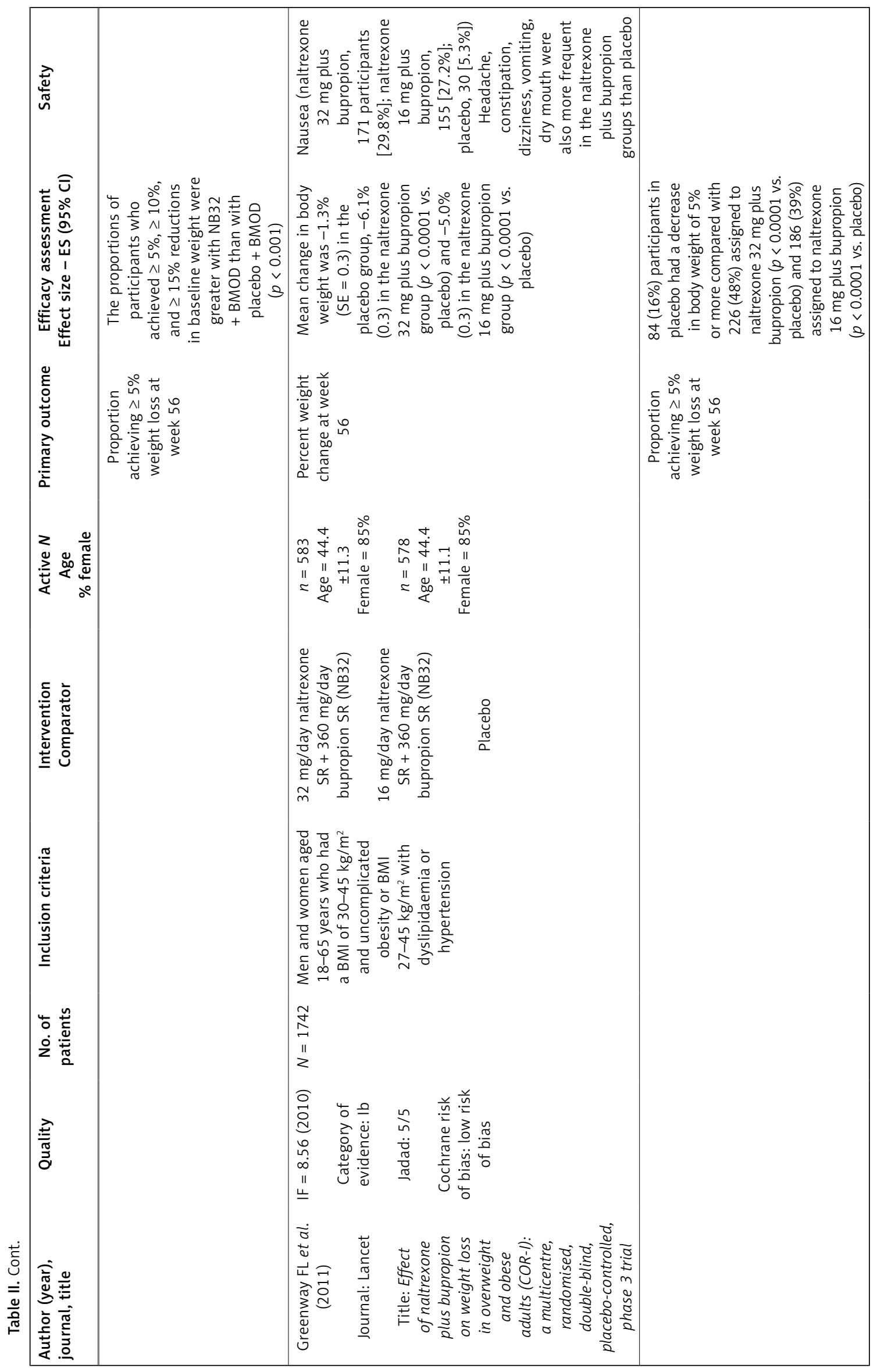


Agnieszka Kulak-Bejda, Grzegorz Bejda, Napoleon Waszkiewicz

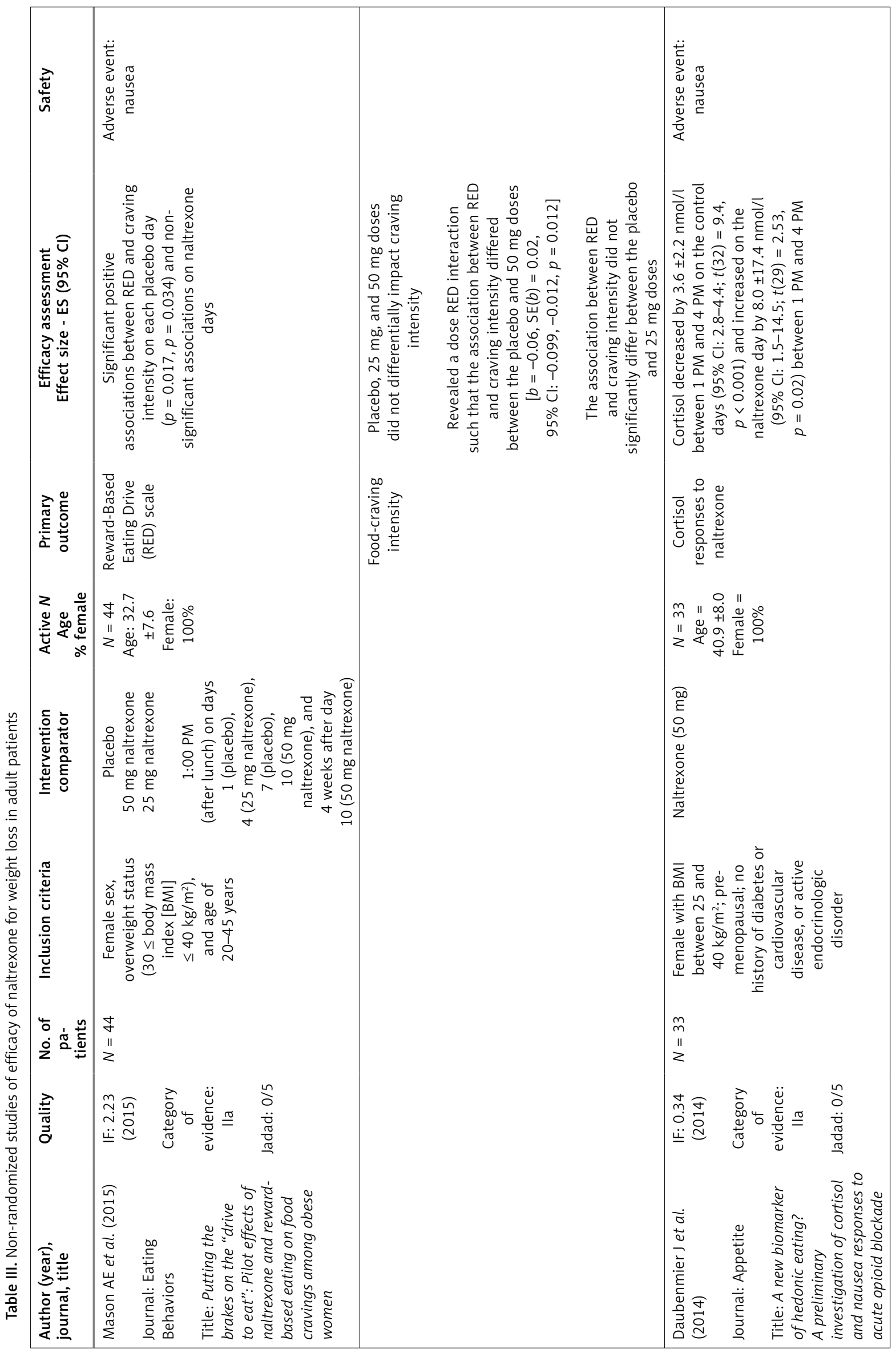




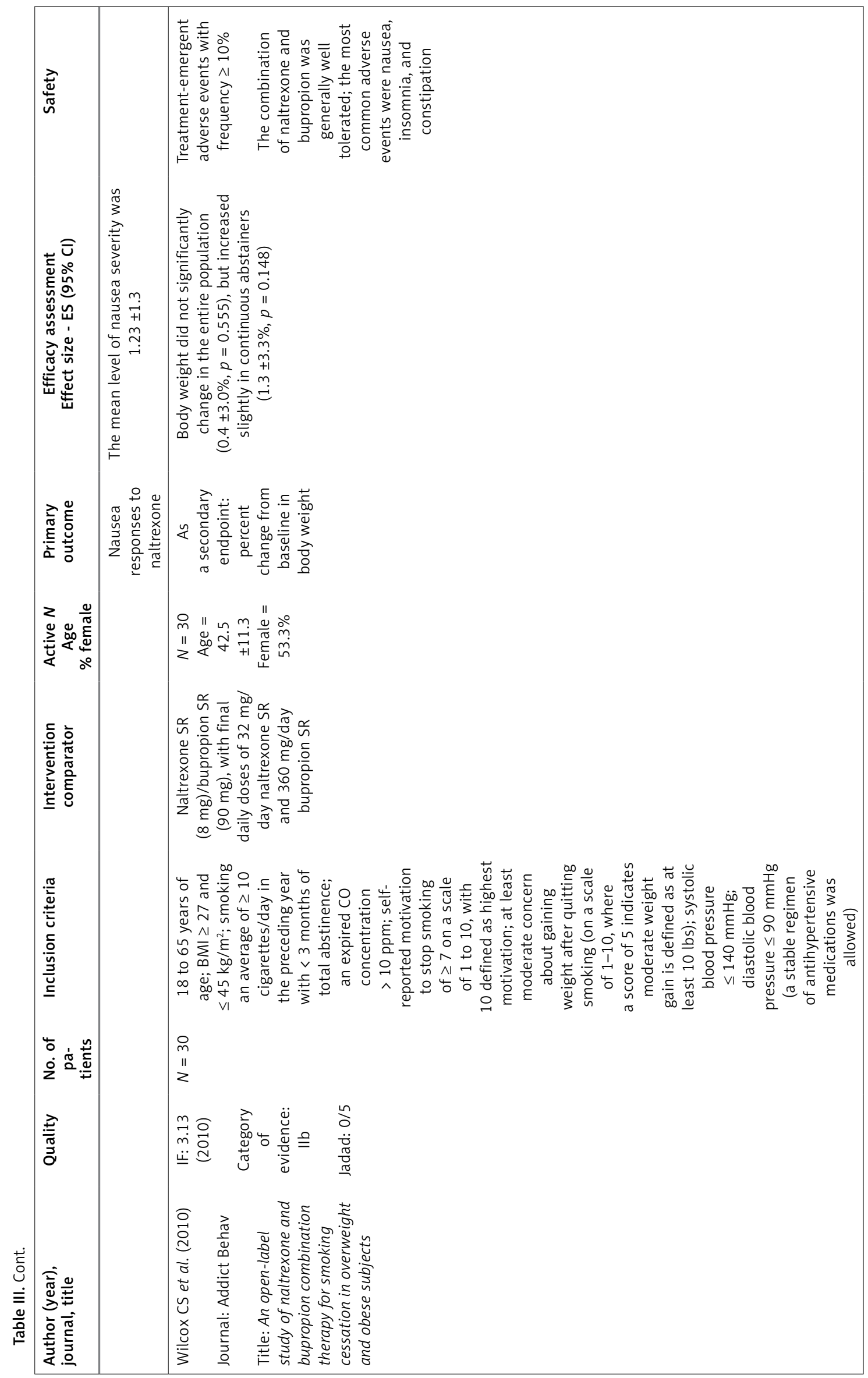


a treatment for body weight in patients with antipsychotic treatment, this combination of medicaments is a subject with limited high-quality research (only two were found) [31, 32]. However, the results of the thirteen articles are promising for intervention with obese subjects after longitudinal treatment. Moreover, naltrexone/bupropion had an influence on cortisol increases [29]. Patients with higher cortisol levels may have greater reductions in food addiction symptoms [29]. This might be useful in the treatment of this group of patients.

In these evaluated studies, we noted enormous heterogeneity, including study protocol, population groups, the period of treatment and the main outcomes. Despite this fact, the heterogeneity might complicate the extrapolation of findings to obese subjects with antipsychotic treatment (only two from thirteen studies used mental health patients as a population) [31, 32]. The authors of the current study decided to include different studies to widen the point of view on the obesity problem. This may contribute to the deepening of the problem of obesity in patients with antipsychotic-associated weight gain in future research projects.

Naltrexone/bupropion treatment can be a promising therapy for obese patients and also for mental health treatment. Based on the above-mentioned studies, naltrexone/bupropion therapy also appears to be safe. Generally, the toleration of naltrexone/ bupropion was good. The most common side effect was nausea. However, based on all of the studies, this choice of therapy should be individual, given entity sensitivity (adverse events caused dropouts).

Moreover, another study [38] showed that naltrexone/bupropion might be useful in reducing binge-eating symptoms related to major depressive disorder and obesity. The authors of that study investigated the relationship between change in eating behaviour and changes in weight, control of eating, and depressive signs. Improvement in eating symptoms was observed between 4 and 24 weeks.

However, another author demonstrated that naltrexone as an opioid-receptor antagonist influences pain tolerance. Also, he showed that naltrexone-induced changes in pain were correlated with depression scores [39].

In conclusion, our systematic review suggests that naltrexone/bupropion treatment is effective in the accomplishment of weight loss amongst overweight subjects. The naltrexone/bupropion treatment was well tolerated by the patients, and side effects were rarely reported.

\section{Conflict of interest}

The authors declare no conflict of interest.

\section{References}

1. Dibaise JK, Foxx-Orenstein AE. Role of the gastroenterologist in managing obesity. Expert Rev Gastroenterol Hepatol 2013; 7: 439-51.

2. Global Health Observatory. Obesity and overweight: World Health Organization 2017. Available at: http:// www.who.int/gho/ncd/risk_factors/overweight/en/.

3. Ogden CL, Flegal KM. Changes in terminology for childhood overweight and obesity. Natl Health Stat Report 2010; 25: 1-5.

4. Lovren $\mathrm{F}$, Teoh $\mathrm{H}$, Verma S. Obesity and atherosclerosis: mechanistic insights. Can J Cardiol 2015; 31: 177-83.

5. Sliwinska A, Kasinska MA, Drzewoski J. MicroRNAs and metabolic disorders - where are we heading? Arch Med Sci 2017; 13: 885-96.

6. The Look AHEAD Research Group. The look AHEAD study: A description of the lifestyle intervention and the evidence supporting it. Obesity 2006; 14: 737-52.

7. Saunders KH, Kumar RH, Igel LI, Aronne LJ. Pharmacologic approaches to weight management: recent gains and shortfalls in combating obesity. Curr Atheroscler Rep 2016; 18: 36.

8. Casey DE, Zorn SH. The pharmacology of weight gain with antipsychotics. J Clin Psychiatry 2001; 62 (Suppl 7): 4-10.

9. Marston OJ, Heisler LK. Targeting the serotonin $2 \mathrm{C}$ receptor for the treatment of obesity and type 2 diabetes. Neuropsychopharmacology 2009; 34: 252-3.

10. Yeomans MR, Gray RW. Opioid peptides and the control of human ingestive behaviour. Neurosci Biobehav Rev 2002; 26: 713-28.

11. Apovian CM, Aronne LJ, Bessesen DH, et al. Pharmacological management of obesity: an endocrine Society clinical practice guideline. J Clin Endocrinol Metab 2015; 100: 342-62.

12. Pucci A, Finer N. New medications for treatment of obesity: metabolic and cardiovascular effects. Can J Cardiol 2015; 31: 142-52.

13. Greenway FL, Whitehouse MJ, Guttadauria M, et al. Rational design of a combination medication for the treatment of obesity. Obesity 2009; 17: 30-9.

14. Greenway FL, Dunayevich E, Tollefson G, et al. Comparison of combined bupropion and naltrexone therapy for obesity with monotherapy and placebo. J Clin Endocrinol Metab 2009; 94: 4898-906.

15. Smith SR, Fujioka K, Gupta AK, et al. Combination therapy with naltrexone and bupropion for obesity reduces total and visceral adiposity. Diabetes Obes Metab 2013; 15: 863-6.

16. Christou GA, Kiortsis DN. The efficacy and safety of the naltrexone/bupropion combination for the treatment of obesity: an update. Hormones 2015; 14: 370-5.

17. Gadde KM, Xiong GL. Bupropion for weight reduction. Expert Rev Neurother 2007; 7: 17-24.

18. Verpeut JL, Bello NT. Drug safety evaluation of naltrexone/bupropion for the treatment of obesity. Expert Opin Drug Saf 2014; 13: 831-41.

19. Jadad AR, Moore RA, Carroll D, et al. Assessing the quality of reports of randomized clinical trials: is blinding necessary? Control Clin Trials 1996; 17: 1-12.

20. Higgins JP, Altman DG, Sterne JAC. Cochrane Handbook for Systematic Reviews of Interventions. Available at: http://handbook.cochrane.org/ (accessed: September 15, 2015).

21. Shekelle PG, Woolf SH, Eccles M, Grimshaw J. Clinical guidelines: developing guidelines. BMJ 1999; 318: 593-6.

22. Khera R, Murad MH, Chandar AK, et al. Association of pharmacological treatments for obesity with weight 
loss and adverse events: a systematic review and meta-analysis. JAMA 2016; 315: 2424-34.

23. Nissen SE, Wolski KE, Prcela L, et al. Effect of naltrexone-bupropion on major adverse cardiovascular events in overweight and obese patients with cardiovascular risk factors: a randomized clinical trial. JAMA 2016; 315: 990-1004.

24. Hollander P, Gupta AK, Plodkowski R, et al. Effects of naltrexone sustained-release/bupropion sustained-release combination therapy on body weight and glycemic parameters in overweight and obese patients with type 2 diabetes. Diabetes Care 2013; 36: 4022-9.

25. Apovian CM, Aronne L, Rubino D, et al. A randomized, phase 3 trial of naltrexone SR/bupropion SR on weight and obesity-related risk factors (COR-II). Obesity 2013; 21: 935-43.

26. Wadden TA, Foreyt JP, Foster GD, et al. Weight loss with naltrexone SR/bupropion SR combination therapy as an adjunct to behavior modification: the COR-BMOD trial. Obesity 2011; 19: 110-20.

27. Greenway FL, Fujioka K, Plodkowski RA, et al. Effect of naltrexone plus bupropion on weight loss in overweight and obese adults (COR-I): a multicentre, randomised, double-blind, placebo-controlled, phase 3 trial. Lancet 2010; 376: 595-605.

28. Halseth A, Shan K, Walsh B, Gilder K, Fujioka K. Method of use study of naltrexone sustained release (SR)/ bupropion SR on body weight in individuals with obesity. Obesity 2017; 5: 338-45.

29. Mason AE, Lustig RH, Brown RR, et al. Acute responses to opioidergic blockade as a biomarker of hedonic eating among obese women enrolled in a mindfulness-based weight loss intervention trial. Appetite 2015; 91: 311-20.

30. Kolotkin RL, Chen S, Klassen P, Gilder K, Greenway FL. Patient-reported quality of life in a randomized placebo-controlled trial of naltrexone/bupropion for obesity. Clin Obes 2015; 5: 237-44.

31. Tek C, Ratliff J, Reutenauer E, Ganguli R, O'Malley SS. A randomized, double-blind, placebo-controlled pilot study of naltrexone to counteract antipsychotic-associated weight gain: proof of concept. J Clin Psychopharmacol 2014; 34: 608-12.

32. Taveira TH, Wu WC, Tschibelu E, et al. The effect of naltrexone on body fat mass in olanzapine-treated schizophrenic or schizoaffective patients: a randomized double-blind placebo-controlled pilot study. J Psychopharmacol 2014; 28: 395-400.

33. Mason AE, Laraia B, Daubenmier J, et al. Putting the brakes on the "drive to eat": pilot effects of naltrexone and reward-based eating on food cravings among obese women. Eat Behav 2015; 19: 53-6.

34. Daubenmier J, Lustig RH, Hecht FM, et al. A new biomarker of hedonic eating? A preliminary investigation of cortisol and nausea responses to acute opioid blockade. Appetite 2014; 74: 92-100.

35. Wilcox CS, Oskooilar N, Erickson JS, et al. An open-label study of naltrexone and bupropion combination therapy for smoking cessation in overweight and obese subjects. Addict Behav 2010; 35: 229-34.

36. Blüher M. Conservative obesity treatment - when and how? Dtsch Med Wochenschr 2015; 140: 24-8.

37. Gao M, Liu D. Gene therapy for obesity: progress and prospects. Discov Med 2014; 17: 319-28.

38. Guerdjikova Al, Walsh B, Shan K, Halseth AE, Dunayevich E, McElroy SL. Concurrent improvement in both binge eating and depressive symptoms with naltrexone/bupropion therapy in overweight or obese subjects with major depressive disorder in an open-label, uncontrolled study. Adv Ther 2017; 34: 2307-15.

39. Price RC, Christou NV, Backman SB, Stone L, Schweinhardt P. Opioid-receptor antagonism increases pain and decreases pleasure in obese and non-obese individuals. Psychopharmacology 2016; 233: 3869-79. 